\title{
Adverse outcomes associated with rapid linear and non-linear patterns of chronic kidney disease progression
}

\author{
Ibrahim Ali ${ }^{1,2^{*}}$, Rajkumar Chinnadurai ${ }^{1}$, Sara T. Ibrahim ${ }^{3}$ and Philip A. Kalra ${ }^{1,2}$
}

\begin{abstract}
Background: Patients with rapidly declining renal function face the dual threat of end-stage renal disease (ESRD) and mortality prior to ESRD. What is less well characterised is whether the pattern of the renal trajectory, linear or non-linear, unmasks subgroups of rapidly progressing patients that face adverse outcomes in a differential manner.

Methods: An individual eGFR slope was applied to all outpatient estimated glomerular filtration rate (eGFR) values for each patient in the Salford Kidney Study from 2002 to 2018 who had at least 2 years follow-up, $\geq 4$ eGFR values and baseline eGFR 15 to $<60 \mathrm{ml} / \mathrm{min} / 1.73 \mathrm{~m}^{2}$. Rapid progression was defined as an annual eGFR slope of $\leq-3 \mathrm{ml} /$ $\mathrm{min} / 1.73 \mathrm{~m}^{2} / \mathrm{yr}$ and patients were categorised as linear or non-linear progressors based on the nature of their eGFRtime graphs. A Fine-Gray competing risk hazard model was used to determine factors associated with progression to ESRD and with mortality prior to ESRD. Cumulative incidence function curves highlighted differences in outcomes between linear and non-linear patients.
\end{abstract}

Results: There were 211 rapidly deteriorating patients with linear eGFR trajectories and 61 rapid non-linear patients in the study cohort. Factors associated with ESRD included younger age, male gender, lower baseline eGFR and higher serum phosphate, whilst older age, history of myocardial infarction and anaemia predicted mortality prior to ESRD. Over a median follow-up of 3.7 years, linear progressors reached ESRD sooner whilst those with non-linear progression faced significantly higher rates of mortality prior to ESRD.

Conclusions: Patients with rapid eGFR decline have high rates of adverse outcomes that are differentially expressed in those progressing linearly and non-linearly as a result of differing phenotypic profiles. Consequently, addressing individual risk factor profiles is important to deliver optimal personalised patient care.

Keywords: Chronic kidney disease, CKD, Linear, Non-linear, Progression, End-stage renal disease, ESRD

\footnotetext{
* Correspondence: ibrahim.ali@srft.nhs.uk

'Department of Renal Medicine, Salford Royal NHS Foundation Trust, Stott Lane, Salford M6 8HD, UK

${ }^{2}$ Division of Cardiovascular Sciences, University of Manchester, Manchester M13 9PL, UK

Full list of author information is available at the end of the article
}

(c) The Author(s). 2021 Open Access This article is licensed under a Creative Commons Attribution 4.0 International License, which permits use, sharing, adaptation, distribution and reproduction in any medium or format, as long as you give appropriate credit to the original author(s) and the source, provide a link to the Creative Commons licence, and indicate if changes were made. The images or other third party material in this article are included in the article's Creative Commons licence, unless indicated otherwise in a credit line to the material. If material is not included in the article's Creative Commons licence and your intended use is not permitted by statutory regulation or exceeds the permitted use, you will need to obtain permission directly from the copyright holder. To view a copy of this licence, visit http://creativecommons.org/licenses/by/4.0/ The Creative Commons Public Domain Dedication waiver (http://creativecommons.org/publicdomain/zero/1.0/) applies to the data made available in this article, unless otherwise stated in a credit line to the data. 


\section{Background}

Patients with chronic kidney disease (CKD) that experience rapidly declining renal function are at increased risk of adverse outcomes, including increased risk of end-stage renal disease (ESRD) as well as increased risk of mortality prior to ESRD [1]. Over the past decade, there has been growing attention to not only considering the slope of renal function change, as defined by annual changes in estimated glomerular filtration rate (eGFR) [2], but also the pattern of the eGFR trajectory on patient outcomes [3, 4], especially given that patients with CKD progress in ways other than in a simply linear manner [5].

Extending our understanding of how the eGFR slope and trajectory impacts patient outcomes could help to refine current risk prediction tools to stratify high-risk patients more accurately. This would help improve the communication of risk to patients and help shape management strategies, including earlier targeted treatment in an attempt to assuage future harm [6].

Whilst several studies have recognised the determinants of rapid progression, what is less well known is whether the pattern of rapid CKD progression, be it linear or non-linear, has an impact on patient outcomes. We therefore undertook this study to 1 ) identify the predictive factors of rapid progression in a cohort of patients progressing in a linear and non-linear pattern; 2) to examine how the pattern of rapid progression affects outcomes of ESRD and mortality prior to ESRD, and in doing so, 3) identify whether there are subgroups and phenotypic differences between linear and non-linear progressors that could enlighten specific approaches to patient management.

\section{Methods}

\section{Patient population}

Patients were drawn from the Salford Kidney Study (SKS), an ongoing observational cohort study, which since 2002 has been recruiting patients aged $\geq 18$ years old with non-dialysis CKD who have been referred to the renal services at Salford Royal NHS Foundation Trust in the United Kingdom. The SKS received ethical approval from the North West Greater Manchester South Research Ethics Committee (REC15/NW/0818). Written informed consent was obtained from all patients. The methods described herein were carried out in accordance with relevant guidelines and regulations of the SKS.

\section{Baseline characteristics}

Patient characteristics were measured at the point of recruitment into the SKS. They include patient demographics (age, gender, ethnicity, history of past or current smoking); past medical history (primary renal disease, history of hypertension (HTN), diabetes mellitus (DM), myocardial infarction (MI), peripheral vascular disease (PVD), stroke and heart failure (HF)); medication history (use of angiotensin converting enzyme inhibitor (ACEi), angiotensin receptor blockers (ARB) and statins); and laboratory measurements (serum creatinine, eGFR calculated using the CKD epidemiology collaboration (CKD-EPI) equation, bicarbonate, urea, calcium, phosphate, albumin, haemoglobin and urine protein:creatinine ratio (uPCR), which was categorised into albuminuria grades of A1, A2 and A3 based on values of $<15 \mathrm{~g} / \mathrm{mol}, 15-50 \mathrm{~g} / \mathrm{mol}$ and $>50 \mathrm{~g} / \mathrm{mol}$ respectively) [7].

\section{Assembling the study cohort}

Patient selection into this study is shown in Fig. 1. All the outpatient eGFR values, performed as part of routine renal care and accessed via the hospital's electronic patient record, were used to calculate the delta $(\Delta)$ eGFR slope for each patient using linear regression. As a minimum, we required at least 4 eGFR values over 2 years follow-up for the $\triangle \mathrm{eGFR}$ to be ascertained for each patient. Patients with a $\Delta \mathrm{eGFR} \leq-3 \mathrm{ml} / \mathrm{min} / 1.73 \mathrm{~m}^{2} / \mathrm{yr}$ (ie. losing more than $3 \mathrm{ml} / \mathrm{min} / 1.73 \mathrm{~m}^{2} / \mathrm{yr}$ ), a threshold associated with worse outcomes [2], were defined as a rapid progressor, and they had to have baseline CKD G3a-4 (eGFR 15 to $<60 \mathrm{ml} / \mathrm{min} / 1.73 \mathrm{~m}^{2}$ ) for study inclusion. To differentiate linear versus non-linear progression, the eGFR-time graphs were visually inspected independently by two clinicians, an approach that has been successfully utilised in previous studies $[1,8]$, and also quantitively assessed with the coefficient of determination $\left(R^{2}\right)$.

\section{Study outcomes}

Patient outcomes included ESRD (haemodialysis, peritoneal dialysis, conservative care or pre-emptive transplantation) or mortality prior to ESRD. Outcome events were reviewed until 1st January 2020.

\section{Statistical analysis}

Continuous data is presented as median ( \pm interquartile range) and categorical data as number (percentage). To compare variables between rapid linear and rapid nonlinear progressors, Mann-Whitney $U$ test was used for continuous data and chi-squared test for categorical covariates. The Fine-Gray competing risk hazard model [9] was employed to determine the sub-distribution hazard ratios of the factors associated with ESRD or mortality prior to ESRD within the study cohort. The following 20 variables were included in the model: age, gender, SBP, DBP, HTN, DM, smoking, MI, PVD, stroke, HF, ACEi/ ARB use, statin use, eGFR, bicarbonate, calcium, 


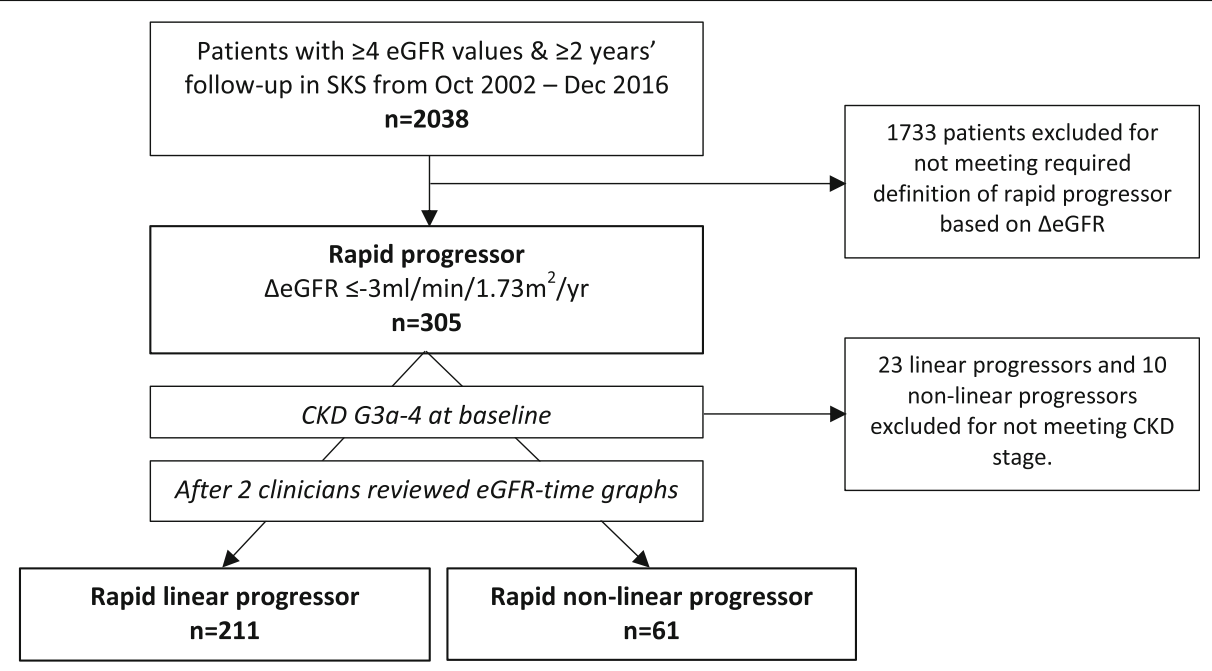

Fig. 1 Assembling the study cohort. Abbreviations: SKS (Salford Kidney Study)

phosphate, albumin, $\mathrm{Hb}$ and $\mathrm{A} 3$ proteinuria. The proportional hazards assumption for each model was assessed by the non-significance of each time-by-variable interaction.

Cumulative incidence function curves were produced comparing the outcomes of ESRD and mortality between linear and non-linear progressors, for which a modified Chi-squared test was used for significance testing [10]. A comparison between linear and non-linear progressors on a composite outcome of either ESRD or mortality was also assessed and visualised as a 1-Kaplan-Meier curve, which used log-rank significance testing. Statistical significance was defined as a $p$ value of $<0.05$. Analyses were performed using SPSS (Version 25.0) (IBM SPSS, Chicago, IL) licensed to the University of Manchester and R version 4.0.2 (The R Foundation for Statistical Computing Platform).

\section{Results}

\section{Baseline characteristics}

A total of 272 patients met the inclusion criteria of which 211 patients had linear progression and 61 patients had non-linear progression (Table 1). Categorisation as a linear or non-linear progressor was achieved with unanimous agreement between the two clinicians independently reviewing patients' eGFR-time graphs, illustrative examples of which are shown in Fig. 2. Quantitatively, linear patients had a significantly higher median $\mathrm{R}^{2}$ value of $0.91(0.81-0.95)$ compared with 0.58 $(0.36-0.60)$ in non-linear progressors, $p$-value $<0.01$.

There were no significant differences in laboratory measures between the two patient groups. Of note, both groups demonstrated poor baseline renal function with a median eGFR of $34 \mathrm{ml} / \mathrm{min} / 1.73 \mathrm{~m}^{2} \quad(26-41 \mathrm{ml} / \mathrm{min} /$ $\left.1.73 \mathrm{~m}^{2}\right)$ and $31 \mathrm{ml} / \mathrm{min} / 1.73 \mathrm{~m}^{2}\left(23-41 \mathrm{ml} / \mathrm{min} / 1.73 \mathrm{~m}^{2}\right)$ in linear and non-linear progressors respectively. Both groups also had high degrees of proteinuria, which was reflected in the majority of patients classified with A3 proteinuria.

The categorisation of the nature of the $\triangle \mathrm{eGFR}$ slope in each patient group was strengthened by a large number of eGFR measurements per patient during the follow-up period with a median of $24(16-36)$ in the linear group and 21 (11-37) in the non-linear group. The $\triangle \mathrm{eGFR}$ itself met the a priori definition of rapid renal decline in both patient groups, and were statistically similar: in linear progressors, the median $\triangle \mathrm{eGFR}$ was $5.28 \mathrm{ml} / \mathrm{min} / 1.73 \mathrm{~m}^{2} / \mathrm{yr}\left(-6.75\right.$ to $-4.11 \mathrm{ml} / \mathrm{min} / 1.73 \mathrm{~m}^{2} /$ yr) and in non-linear progressors the $\triangle \mathrm{eGFR}$ was -4.57 $\mathrm{ml} / \mathrm{min} / 1.73 \mathrm{~m}^{2} / \mathrm{yr} \quad\left(-6.46\right.$ to $\left.-3.46 \mathrm{ml} / \mathrm{min} / 1.73 \mathrm{~m}^{2} / \mathrm{yr}\right)$; $p$-value of 0.06 .

There were however significant differences between the progressor groups with respect to demographic characteristics and co-morbidities. Non-linear patients were typically older and had a higher burden of comorbidities including diabetes, myocardial infarction, peripheral vascular disease and heart failure. There was also contrasting frequencies of the underlying disease aetiology, most notably seen for autosomal dominant polycystic kidney disease (ADPKD), which was exclusively associated with linear progressors and was the commonest primary renal disease in this group, affecting a quarter of all linear progressor patients.

Factors associated with ESRD and mortality prior to ESRD Univariate analyses of the factors associated with ESRD is presented in Additional file 1: Tables S1. In multivariate analysis, younger age, male gender, lack of diabetes, lower eGFR and higher phosphate were significantly associated with progression to ESRD (Table 2). 
Table 1 Baseline characteristics of the study cohort

\begin{tabular}{|c|c|c|c|c|}
\hline Variable & $\begin{array}{l}\text { All patients } \\
(n=272)\end{array}$ & $\begin{array}{l}\text { Rapid linear progressor } \\
(n=211)\end{array}$ & $\begin{array}{l}\text { Rapid non-linear progressor } \\
(n=61)\end{array}$ & p-value \\
\hline Age (years) & $58.0(46.0-70.0)$ & $54.8(44.9-67.2)$ & $67.4(58.9-74.5)$ & $<0.01$ \\
\hline Men, $n(\%)$ & $134(49)$ & $104(49)$ & $30(49)$ & 0.99 \\
\hline Caucasian, $n(\%)$ & $231(85)$ & $171(81)$ & $60(98)$ & $<0.01$ \\
\hline Systolic blood pressure $(\mathrm{mmHg})$ & $140(128-155)$ & $140(128-154)$ & $140(129-156)$ & 0.75 \\
\hline Diastolic blood pressure (mmHg) & $78(70-84)$ & $79(70-84)$ & $76(70-81)$ & 0.17 \\
\hline Hypertension, $n$ (\%) & $254(93)$ & $197(93)$ & $57(93)$ & 0.98 \\
\hline Diabetes, $n(\%)$ & $90(33)$ & $59(28)$ & $31(51)$ & $<0.01$ \\
\hline Past/current smoking history, $n$ (\%) & $174(64)$ & $132(63)$ & $42(69)$ & 0.37 \\
\hline Myocardial infarction, n (\%) & $26(10)$ & $12(6)$ & $14(23)$ & $<0.01$ \\
\hline Peripheral vascular disease, $n(\%)$ & $33(12)$ & $20(10)$ & $13(21)$ & 0.01 \\
\hline Stroke, $n(\%)$ & $20(7)$ & $12(6)$ & $8(13)$ & 0.05 \\
\hline Heart failure, $n(\%)$ & $27(10)$ & $13(6)$ & $14(23)$ & $<0.01$ \\
\hline ACEi/ARB, $n(\%)$ & $197(72)$ & $158(75)$ & $39(64)$ & 0.09 \\
\hline Statin, $n(\%)$ & $158(58)$ & $120(57)$ & $38(62)$ & 0.45 \\
\hline Years follow-up & $3.7(2.8-4.9)$ & $3.9(2.9-5.0)$ & $3.2(2.6-4.0)$ & $<0.01$ \\
\hline \multicolumn{5}{|l|}{ Primary renal disease } \\
\hline Diabetic nephropathy, n (\%) & $67(25)$ & $46(22)$ & $21(34)$ & 0.04 \\
\hline ADPKD, $n(\%)$ & $55(20)$ & $55(26)$ & $0(0)$ & $<0.01$ \\
\hline Hypertensive nephropathy, n (\%) & $26(10)$ & $15(7)$ & $11(18)$ & 0.01 \\
\hline Glomerulonephritis, n (\%) & $34(13)$ & $32(15)$ & $2(3)$ & 0.01 \\
\hline Other causes, $n(\%)$ & $66(24)$ & $45(21)$ & $21(23)$ & 0.04 \\
\hline Unknown, $n(\%)$ & $24(9)$ & $18(9)$ & $6(10)$ & 0.75 \\
\hline \multicolumn{5}{|l|}{ Laboratory results } \\
\hline eGFR-EPI $\left(\mathrm{ml} / \mathrm{min} / 1.73 \mathrm{~m}^{2}\right)$ & $34(26-41)$ & $34(26-41)$ & $32(23-41)$ & 0.36 \\
\hline eGFR measurements per patient, $n$ & $24(15-37)$ & $24(16-36)$ & $21(11-37)$ & 0.19 \\
\hline$\Delta \mathrm{GFR}\left( \pm \mathrm{ml} / \mathrm{min} / 1.73 \mathrm{~m}^{2} / \mathrm{yr}\right)$ & $-5.23(-6.72$ to -3.98$)$ & $-5.28(-6.75$ to -4.11$)$ & $-4.57(-6.46$ to -3.46$)$ & 0.06 \\
\hline Bicarbonate $(\mathrm{mmol} / \mathrm{L})$ & $22.6(20.4-25.0)$ & $22.5(20.4-25.0)$ & $23.0(20.6-25.2)$ & 0.43 \\
\hline Urea (mmol/L) & $12.2(9.8-15.7)$ & $12.0(9.9-15.4)$ & $13.9(10.1-17.2)$ & 0.24 \\
\hline Calcium (mmol/L) & $2.31(2.23-2.39)$ & $2.30(2.22-2.34)$ & $2.32(2.27-2.40)$ & 0.15 \\
\hline Phosphate (mmol/L) & $1.13(1.02-1.27)$ & $1.15(1.02-1.28)$ & $1.11(1.03-1.25)$ & 0.74 \\
\hline Albumin $(\mathrm{g} / \mathrm{L})$ & $42(39-44)$ & $41(39-44)$ & $42(39-44)$ & 0.99 \\
\hline Total cholesterol/HDL ratio & $3.4(2.7-4.3)$ & $3.5(2.7-4.5)$ & $3.2(2.6-4.1)$ & 0.16 \\
\hline Haemoglobin (g/L) & $122(113-133)$ & $123(114-133)$ & $121(110-132)$ & 0.57 \\
\hline Urine protein:creatinine ratio $(\mathrm{g} / \mathrm{mol})$ & 77 (24-244) & $87(26-272)$ & $52(24-171)$ & 0.16 \\
\hline A1 proteinuria $(<15 \mathrm{~g} / \mathrm{mol}), n(\%)$ & $33(12)$ & $26(12)$ & $7(12)$ & 0.86 \\
\hline A2 proteinuria $(15-50 \mathrm{~g} / \mathrm{mol}), n(\%)$ & $82(30)$ & $59(28)$ & $23(38)$ & 0.14 \\
\hline A3 proteinuria (> $50 \mathrm{~g} / \mathrm{mol}), n(\%)$ & $157(58)$ & $126(60)$ & $31(51)$ & 0.22 \\
\hline
\end{tabular}

Continuous data are presented as median (interquartile range) and categorical variables presented as number (percentage)

$P$-values, comparing linear and non-linear groups, were calculated by Mann-Whitney test and Chi-squared test for continuous and categorical data respectively Abbreviations: ADPKD (autosomal dominant polycystic kidney disease), ACEi (angiotensin-converting enzyme inhibitor), ARB (angiotensin receptor blocker), eGFR-EPI (eGFR calculated using the EPI-equation)

Three clinical factors were shown to be significantly predictive for mortality prior to ESRD, including older age, history of MI and anaemia (Table 2). Of note, in univariate analyses (Additional file 1: Tables S2), higher
SBP, history of diabetes, smoking, PVD, HF and lack of $\mathrm{ACEi} / \mathrm{ARB}$ use were associated with mortality prior to ESRD but these were found to not be significant once adjusted for other variables. 

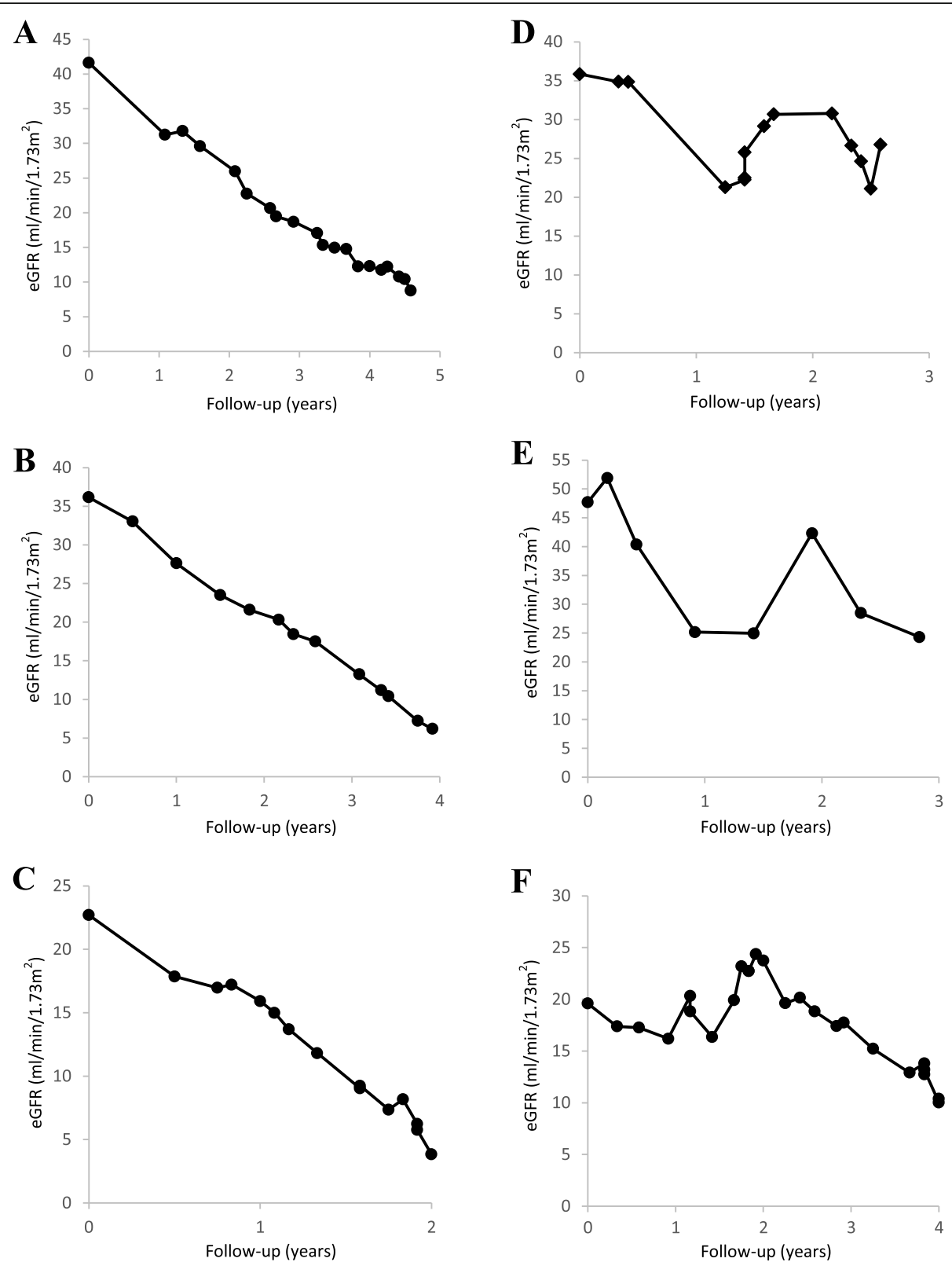

Fig. 2 Examples of eGFR-time graphs of linear and non-linear progressors in the study cohort. Graphs A to C highlight examples of rapid linear progression, whilst graphs D to F show rapid non-linear eGFR trajectory

\section{Survival analysis comparing linear and non-linear progressors}

The study cohort had a median follow-up of 3.7 years (2.8-4.9 years), during which time there were 173 patients who reached ESRD and 81 patients who died prior to ESRD (Table 3). Cumulative incidence function curves (Fig. 3) revealed that rapid linear patients were more likely to develop ESRD compared to their nonlinear counterparts $(p$-value $<0.01)$, but that non-linear progressors suffered higher rates of death prior to ESRD ( $p$-value $<0.01)$. However, when the outcomes were combined as a single endpoint of either ESRD or mortality prior to ESRD (Fig. 4), there was no statistical difference between rapid linear or non-linear progressors ( $p$-value 0.08$)$.

\section{Discussion}

This study highlights the differential impact of the pattern of renal trajectory on adverse outcomes in patients with rapidly deteriorating renal function. Patients with rapid linear progression face higher rates of ESRD sooner whilst those with non-linear progression experience higher rates of mortality prior to ESRD. 
Table 2 Sub-distribution hazard ratios for the competing risks of ESRD and mortality based on a Fine-Gray model

\begin{tabular}{|c|c|c|c|c|c|c|}
\hline & Mortalit & SRD & & ESRD & & \\
\hline & Sub-HR & $95 \% \mathrm{Cl}$ & $p$-value & Sub-HR & $95 \% \mathrm{Cl}$ & p-value \\
\hline Age & 1.06 & $1.04-1.08$ & $<0.01$ & 0.97 & $0.95-0.98$ & $<0.01$ \\
\hline Male & 1.23 & $0.72-2.14$ & 0.46 & 1.49 & $1.03-2.16$ & 0.03 \\
\hline SBP & 1.01 & $0.99-1.02$ & 0.43 & 1.01 & $1.00-1.02$ & 0.09 \\
\hline DBP & 0.99 & $0.96-1.01$ & 0.30 & 1.01 & $0.99-1.02$ & 0.43 \\
\hline Hypertension & 1.27 & $0.30-5.45$ & 0.75 & 0.68 & $0.36-1.30$ & 0.24 \\
\hline Diabetes & 1.36 & $0.78-2.36$ & 0.28 & 0.63 & $0.41-0.98$ & 0.04 \\
\hline Smoking & 1.46 & $0.82-2.59$ & 0.20 & 0.89 & $0.62-1.29$ & 0.55 \\
\hline $\mathrm{Ml}$ & 2.49 & $1.35-4.61$ & 0.04 & 0.36 & $0.11-1.15$ & 0.08 \\
\hline CCF & 1.08 & $0.58-2.00$ & 0.81 & 0.80 & $0.35-1.83$ & 0.60 \\
\hline Stroke & 1.00 & $0.38-2.64$ & 0.99 & 0.67 & $0.30-1.52$ & 0.34 \\
\hline PVD & 1.22 & $0.63-2.33$ & 0.56 & 0.98 & $0.53-1.83$ & 0.95 \\
\hline ACEi/ARB & 0.63 & $0.39-1.01$ & 0.06 & 1.06 & $0.71-1.58$ & 0.77 \\
\hline Statin & 0.79 & $0.45-1.37$ & 0.40 & 1.32 & $0.92-1.91$ & 0.13 \\
\hline eGFR & 1.01 & $0.98-1.03$ & 0.48 & 0.96 & $0.94-0.97$ & $<0.01$ \\
\hline Bicarbonate & 1.00 & $0.94-1.07$ & 0.89 & 1.02 & $0.97-1.08$ & 0.49 \\
\hline Calcium & 0.92 & $0.22-3.87$ & 0.91 & 0.48 & $0.15-1.48$ & 0.20 \\
\hline Phosphate & 0.38 & $0.10-1.42$ & 0.15 & 3.15 & $1.29-7.67$ & 0.01 \\
\hline Albumin & 1.00 & $0.95-1.05$ & 0.83 & 0.99 & $0.95-1.02$ & 0.43 \\
\hline Haemoglobin & 0.97 & $0.95-0.99$ & 0.02 & 1.00 & $0.99-1.01$ & 0.86 \\
\hline A3 proteinuria & 0.58 & $0.34-1.00$ & 0.05 & 1.00 & $0.71-1.42$ & 0.99 \\
\hline
\end{tabular}

Abbreviations: SBP (systolic blood pressure), DBP (diastolic blood pressure), MI (myocardial infarction), CCF (congestive heart failure), PVD (peripheral vascular disease), ACEi (angiotensin converting enzyme inhibitor), ARB (angiotensin receptor blocker), eGFR-EPI (eGFR calculated using the EPI-equation)

\section{Patterns of progression and determinants of adverse outcomes}

Our cohort of rapid progressors was predominantly comprised of patients with linear progression, with only $22 \%$ of patients deemed to have non-linear progression. This corroborates with work by Weldegiorgis et al. [11], who showed that the majority of the 3523 pooled patients with CKD from six randomised trials demonstrated linear eGFR decline. For instance, they reported a $>50 \%$ probability of non-linear progression in 15.1 to $21.2 \%$ of patients from non-diabetic kidney trials and 19.3 to $31.7 \%$ in diabetic kidney trials.

With respect to the determinants of adverse outcomes, previous work has shown that younger age [12], male gender [13, 14], lower eGFR [7] and higher phosphate
[15] are all independently associated with ESRD, and this was borne out in our analysis. In addition, we found that older age [12], a history of MI [16-18], and anaemia [19] are significant determinants of mortality prior to ESRD, and these findings again align with the reported literature. Thus, in our cohort of clearly characterised linear and non-linear progressors, we show the expected overlap of predictive factors important to those who rapidly progress. However, we notably found a lack of diabetes to be predictive for ESRD and also found that A3 proteinuria was not predictive of worse outcomes in our analysis. These findings may likely be attributed to the specific disease characteristics in our population. Indeed, $20 \%$ of the entire cohort had ADPKD, of whom $87 \%$ reached ESRD. Of the 55 patients with ADPKD only 1

Table 3 Outcome data

\begin{tabular}{lll}
\hline & $\begin{array}{l}\text { Rapid linear progressor } \\
(\mathbf{n = 2 1 1 )}\end{array}$ & $\begin{array}{l}\text { Rapid non-linear progressor } \\
(\mathbf{n = 6 1 )}\end{array}$ \\
\hline ESRD, $n(\%)$ & $156(76)$ & $17(28)$ \\
Death prior to ESRD, $n(\%)$ & $43(20)$ & $9(62)$ \\
Under follow-up, $n(\%)$ & $9(4)$ & $3(1)$ \\
Care transferred to another hospital, $n(\%)$ & $1(2)$ \\
\hline
\end{tabular}




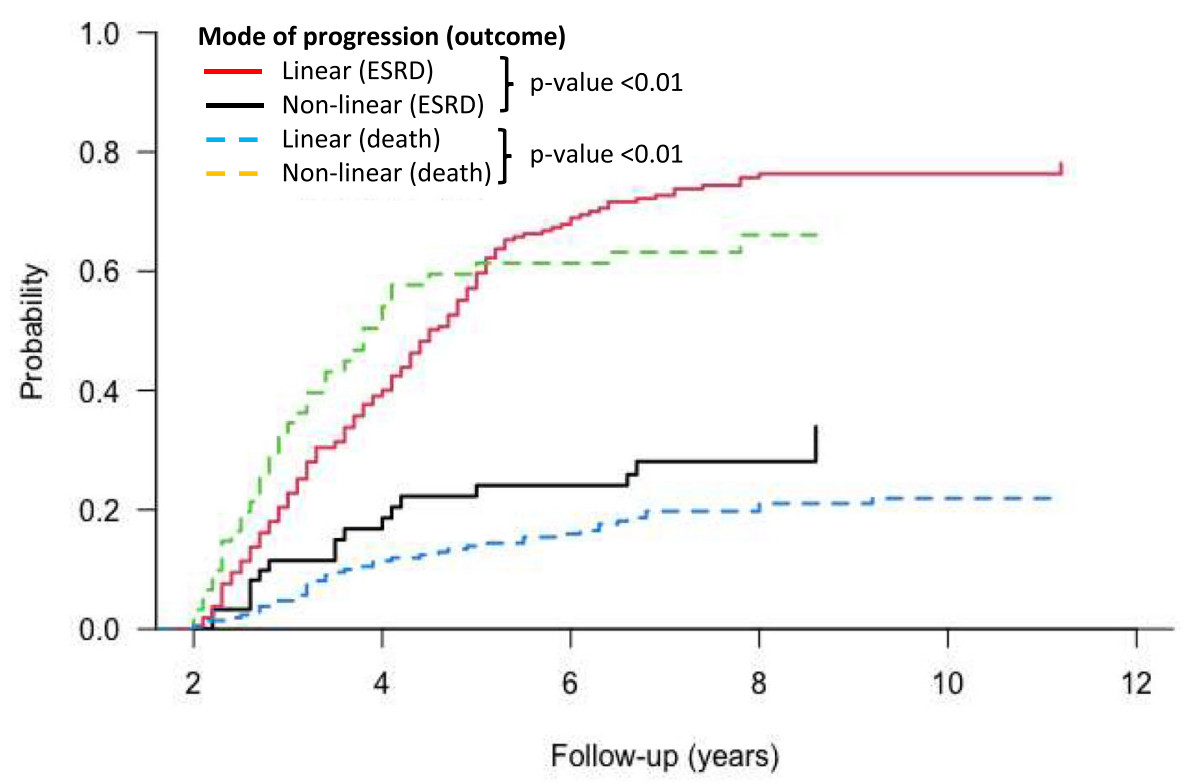

Numbers at risk

$\begin{array}{lcccccc}\text { Linear } & 211 & 103 & 30 & 7 & 2 & 0 \\ \text { Non-linear } & 61 & 18 & 8 & 2 & 0 & 0\end{array}$

Fig. 3 Cumulative incidence functions for ESRD and death prior to ESRD compared between linear and non-linear progressors. Abbreviations: ESRD (end-stage renal disease)

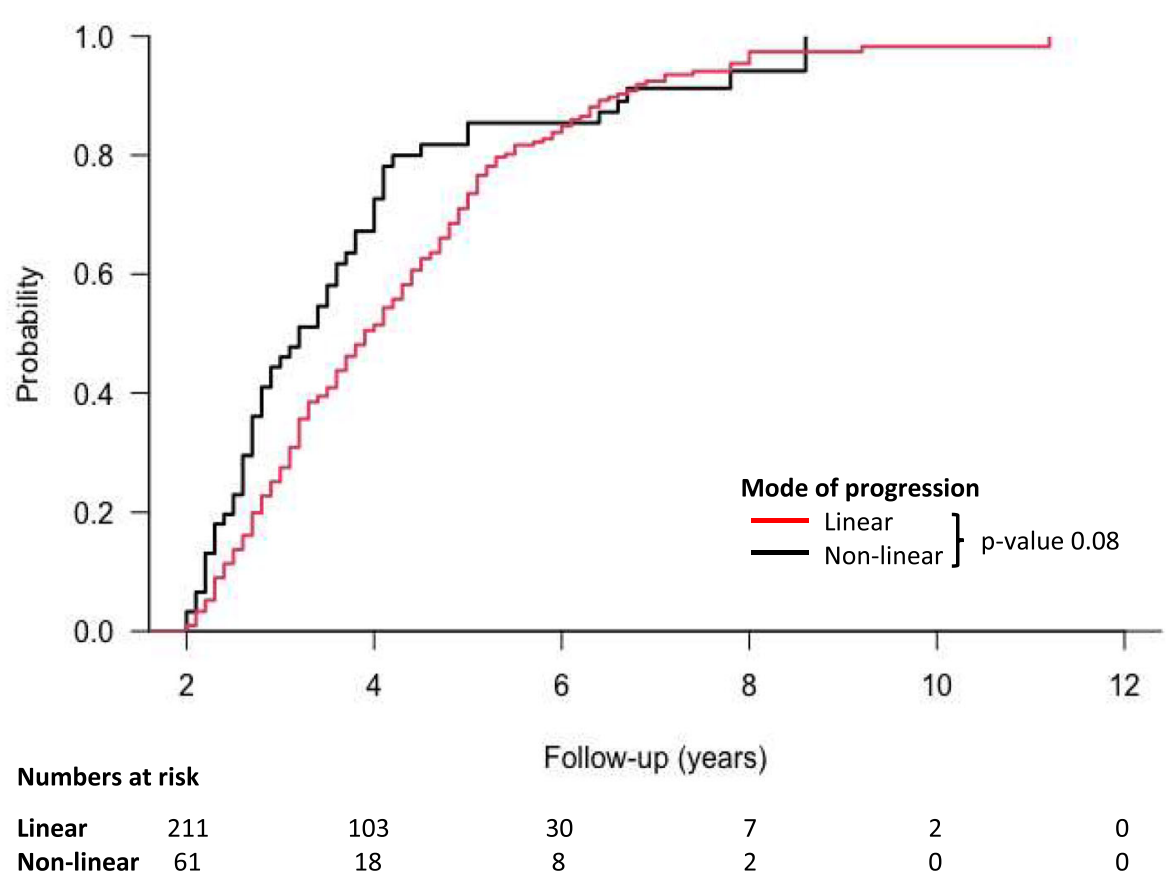

Fig. 4 1-Kaplan-Meier curves for probability of survival from the composite outcome of either ESRD or death prior to ESRD compared between linear and non-linear progressors 
(2\%) had diabetes and 8 (15\%) were classed as having A3 proteinuria (Additional file 1: Table S3), and this may have affected the impact of diabetes and A3 proteinuria on our outcomes in this cohort.

What is less well known is the association of the pattern of rapid CKD progression, either linear or nonlinear, on outcomes such as ESRD and mortality. We hypothesised that rapid linear progressors would fare significantly worse than non-linear progressors, largely as a result of the inevitable culmination of ESRD in linear progressors, whereas potential fluctuating phases of stability may offer a degree of protection to those with non-linear renal decline. We discovered that whilst linear progressors do indeed reach ESRD sooner, nonlinear patients were at a significantly greater risk of the competing event of death prior to ESRD.

Phenotypic differences between the two patient groups can help to unravel these findings. For instance, the primary renal disease in $26 \%$ of the rapid linear progressors was ADPKD, a condition typically characterised by a linear trajectory to ESRD [20], as a result of the unremitting enlargement of renal cysts that eventually destroy the normal renal architecture.

Furthermore, we found non-linear patients were significantly older, suffered from diabetes and cardiovascular co-morbidities, including MI, PVD and HF. It is conceivable that such patients experience non-linear fluctuations in renal function, including acute kidney injury (AKI), due to uncorrected alterations in their fluid status, as is seen in decompensated heart failure [21]. Additional adjustments to their medications with uptitration of diuretics or with ACEi and ARBs may also cause transient and abrupt eGFR decline. It is clear that the greater burden of cardiovascular disease and the propensity for outpatient AKI-on-CKD events [22] explains the increased mortality experienced by non-linear progressors observed in our cohort.

\section{Clinical implications}

In considering the pattern of CKD progression, we show how two distinct subtypes of rapid progression, linear and non-linear, affect outcomes differentially, which can be explained by differences in patient characteristics. This provides the basis for delivering personalised care to patients, dictated by their disease aetiology, risk factor profile and pattern of CKD progression, and highlights how in some patients the risk of death supersedes the need to prepare for ESRD [6]. This will no doubt influence the communication of risk imparted to patients and help direct the shape of future treatment. Further research in this area is of importance not least because patient heterogeneity for future adverse outcomes is not adequately captured within the current KDIGO staging for CKD, which is based on eGFR and urine albumin: creatinine ratio alone [7]. The future of precision medicine, therefore, relies upon the establishment of improved and refined models that can accurately risk stratify specific CKD patient subgroups.

However, whilst there are specific differences between linear and non-linear progressors with respect to outcomes, there was no survival difference in our analysis between the patients when combining the outcomes as a composite endpoint. Based on this, it is important to emphasise the risk conferred to patients from rapid renal decline per se, irrespective of the underlying pattern of progression. In effect, therefore, early identification of rapid progression should prompt close monitoring and aggressive risk factor modification to stabilise and curb a falling eGFR trajectory as best as possible.

Furthermore, this study highlights the significance of estimating $\triangle \mathrm{eGFR}$ for predicting future outcomes. Indeed, in addition to the last eGFR level, the past eGFR trend has been shown to predict a patient's future risk of ESRD, especially those with advanced CKD in whom the absolute risk of ESRD is higher [23]. This raises the question as to whether $\triangle \mathrm{eGFR}$ can be incorporated into current risk prediction tools such as the well-validated Kidney Failure Risk Equation (KFRE), which predicts the 2- and 5-year risk of ESRD in patients with CKD stage 3-5 [15]. However, given that it is equally relevant to reconcile whether death may be more likely than ESRD, the CKD Prognosis Consortium risk calculator provides the 2- and 4-year risk of ESRD as well as the risk of non-fatal cardiovascular events and death prior to ESRD in patients with CKD stage 4, and provides an estimation of the timing of these events in relation to ESRD [24]. Again, whether quantification of the $\triangle \mathrm{eGFR}$ could improve the risk score in this prediction tool is an area for future research. Further work is also required to determine what time period the $\triangle \mathrm{eGFR}$ should be assessed over. For instance, does inclusion of a patient's $\triangle \mathrm{eGFR}$ calculated over the last year, last 2-years or over a longer time period improve predictive utility over current risk prediction models?

\section{Strengths and limitations}

This study extends our understanding of CKD progression by providing a closer examination of linear and non-linear patterns of rapid progression on future clinical endpoints. It is strengthened by a systematic approach to patient selection that characterises the CKD pattern robustly.

There are also limitations to our work. By its nature of being an observational study, we could not confirm causal association or fully account for unmeasured confounders. In addition, it is a single-centre study with a predominantly Caucasian population and thus the 
findings may not be generalisable to other patient populations.

\section{Conclusions}

Patients who progress rapidly are exposed to the dual threat of ESRD or mortality prior to ESRD. However, differences in patient characteristics exist between those who progress rapidly in a linear or non-linear fashion, and this has a significant bearing on observed future outcomes. Thus, the phenotypic risk factor profile and individual eGFR trajectory should provide the substrate for personalised therapeutic interventions in this highly vulnerable group of patients in order to deliver optimal CKD care.

\section{Abbreviations}

ACEi: Angiotensin converting enzyme inhibitor; AKl: Acute kidney injury; ARB: Angiotensin receptor blocker; ADPKD: Autosomal dominant polycystic kidney disease; CKD: Chronic kidney disease; Cl: Confidence interval; $\triangle$ eGFR: Delta estimated glomerular filtration rate; DM: Diabetes mellitus; DBP: Diastolic blood pressure; ESRD: End-stage renal disease; eGFR: Estimated glomerular filtration rate; Hb: Haemoglobin; HF: Heart failure; Ml: Myocardial infarction; PVD: Peripheral vascular disease; SBP: Systolic blood pressure. SKS: Salford Kidney Study; uPCR: Urine protein:creatinine ratio

\section{Supplementary Information}

The online version contains supplementary material available at https://doi. org/10.1186/s12882-021-02282-5.

Additional file 1: Table S1. Univariate analysis using Fine-Gray hazards model to investigate factors associated with ESRD. Table S2. Univariate analysis using Fine-Gray hazard model to investigate factors associated with mortality prior to ESRD. Table S3. Baseline characteristics of patients with autosomal dominant polycystic kidney disease, diabetic nephropathy and glomerulonephritis.

\section{Acknowledgements}

None.

\section{Authors' contributions}

IA and PAK conceived the study. IA performed data collection, statistical analysis and wrote the initial draft. RC conducted linear regression calculations. STI supported in patient selection. IA and PAK critically revised the article. All authors read and approved the final manuscript.

\section{Funding}

None.

\section{Availability of data and materials}

The data analysed during the current study are available from the corresponding author on reasonable request.

\section{Declarations}

Ethics approval and consent to participate

The Salford Kidney Study was granted ethical approval by the North West Greater Manchester South Research Ethics Committee (REC15/NW/0818). Written informed consent was obtained from all patients. The methods described herein were carried out in accordance with relevant guidelines and regulations of the SKS.

\section{Consent for publication}

Not applicable.

\section{Competing interests}

The authors declare no competing interests.

\section{Author details}

${ }^{1}$ Department of Renal Medicine, Salford Royal NHS Foundation Trust, Stott Lane, Salford M6 8HD, UK. ²Division of Cardiovascular Sciences, University of Manchester, Manchester M13 9PL, UK. ${ }^{3}$ Department of Internal Medicine and Nephrology, Faculty of Medicine, Alexandria University, Alexandria, Egypt.

Received: 25 October 2020 Accepted: 25 February 2021

Published online: 06 March 2021

\section{References}

1. Ali I, Chinnadurai R, Ibrahim ST, Green D, Kalra PA. Predictive factors of rapid linear renal progression and mortality in patients with chronic kidney disease. BMC Nephrol. 2020;21:345.

2. Rosanksy SJ. Renal function trajectory is more important than chronic kidney disease stage for managing patients with chronic kidney disease. Am J Nephrol. 2012;36:1-10.

3. Collister D, Ferguson T, Komenda P, Tangri N. The patterns, risk factors, and prediction of progression in chronic kidney disease: a narrative review. SeminNephrol. 2016:36:273-82

4. Caravaca-Fontán F, Azevedo L, Luna E, Caravaca F. Patterns of progression of chronic kidney disease at later stages. Clin Kidney J. 2018;11:246-53.

5. Li L, Astor BC, Lewis J, Hu B, Appel LJ, Lipkowitz MS, et al. Longitudinal progression trajectory of GFR among patients with CKD. Am J Kidney Dis. 2012;59:504-12

6. Sumida K, Kovesdy CP. Disease trajectories before ESRD: implications for clinical management. Semin Nephrol. 2017;37:132-43.

7. Levey AS, de Jong PE, Coresh J, El Nahas M, Astor BC, Matsushita K, et al. The definition, classification, and prognosis of chronic kidney disease: a KDIGO controversies conference report. Kidney Int. 2011;80:17-28.

8. Agarwal R, Duffin K, Laska DA, Voelker JR, Brever MD, Mitchell PG. A prospective study of multiple protein biomarkers to predict progression in diabetic chronic kidney disease. Nephrol Dial Transplant. 2014;29:2293-302.

9. Fine J, Gray R. A proportional hazards model for the subdistribution of a competing risk. J Am Stat Assoc. 1999;94:496-509.

10. Gray RJ. A class of K-sample tests for comparing the cumulative incidence of a competing risk. Ann Stat. 1988;16:1141-54.

11. Weldegiorgis M, de Zeeuw D, Li L, Parving HH, Hou FF, Remuzzi G, et al. Longitudinal estimated GFR trajectories in patients with and without type 2 diabetes and nephropathy. Am J Kidney Dis. 2018;71:91-101.

12. Levin A, Djurdjev O, Beaulieu M, Er L. Variability and risk factors for kidney disease progression and death following attainment of stage 4 CKD in a referred cohort. Am J Kidney Dis. 2008;52:661-71.

13. Eriksen BO, Ingrebetsen OC. The progression of chronic kidney disease: a 10-year population-based study of the effects of gender and age. Kidney Int. 2006;69:375-82

14. Rebholz CM, Coresh J, Ballew SH, McMahon B, Whelton SP, Selvin E, et al. Kidney failure and ESRD in the atherosclerosis risk in communities (ARIC) study: comparing ascertainment of treated and untreated kidney failure in a cohort study. Am J Kidney Dis. 2015:66:231-9.

15. Tangri N, Grams ME, Levey AS, Coresh J, Appel LJ, Astor BC, et al. Multinational assessment of accuracy of equations for predicting risk of kidney failure. A meta-analysis. JAMA. 2016;315:164-74.

16. Potier L, Roussel R, Zeller M, Schiele F, Puymirat E, Simon T, et al. Chronic kidney disease, diabetes, and risk of mortality after acute myocardial infarction: insight from the FAST-MI program. Diabetes Care. 2020;43:e43-4.

17. Shilpak MG, Heidenreich PA, Noguchi H, Chertow GM, Browner WS, McCellan MB. Association of renal insufficiency with treatment and outcomes after myocardial infarction in elderly patients. Ann Intern Med. 2002;137:555-62.

18. Margolis G, Vig S, Flint N, Khoury S, Barkagan M, Keren G, et al. Prognostic implications of chronic kidney disease on patients presenting with STsegment elevation myocardial infarction with versus without stent thrombosis. Cardiorenal Med. 2017;7:150-7.

19. Toft G, Heide-Jørgensen U, van Haalen H, Glen J, Hedman K, Birn H, et al. Anemia and clinical outcomes in patients with non-dialysis dependent or dialysis dependent severe chronic kidney disease: a Danish populationbased study. J Nephrol. 2020;33:147-56 
20. Hunsicker LG, Adler S, Caggiula A, England BK, Greene T, Kusek JW, et al. Predictors of the progression of renal disease in the modification of diet in renal disease study. Kidney Int. 1997;51:1908-19.

21. Rangaswami J, Bhalla V, Blair JEA, Chang TI, Costa S, Letine KL, et al. Cardiorenal syndrome: classification, pathophysiology, diagnosis, and treatment strategies: a scientific statement from the American Heart Association. Circulation. 2019;139:e840-78.

22. Yeh HC, Ting IW, Huang HC, Chiang H-Y, Kuo C-C. Acute kidney injury in the outpatient setting associates with risk of end-stage renal disease and death in patients with CKD. Sci Rep. 2019;9:17658.

23. Kovesdy CP, Coresh J, Ballew SH, Woodward M, Levin A, Naimark DM, et al. Past decline versus current eGFR and subsequent ESRD risk. J Am Soc Nephrol. 2016;27:2447-55.

24. Grams ME, Sang Y, Ballew SH, Carrero JJ, Djurdjev O, Heerspink HJL, et al. Predicting timing of clinical outcomes in patients with chronic kidney disease and severely decreased glomerular filtration rate. Kidney Int. 2018; 93:1442-51.

\section{Publisher's Note}

Springer Nature remains neutral with regard to jurisdictional claims in published maps and institutional affiliations.

Ready to submit your research? Choose BMC and benefit from:

- fast, convenient online submission

- thorough peer review by experienced researchers in your field

- rapid publication on acceptance

- support for research data, including large and complex data types

- gold Open Access which fosters wider collaboration and increased citations

- maximum visibility for your research: over $100 \mathrm{M}$ website views per year

At $\mathrm{BMC}$, research is always in progress.

Learn more biomedcentral.com/submissions 